\title{
Siete notas sobre una señorita muy fin de siglo
}

\author{
Alberto PAREDES \\ Universidad Nacional Autónoma de México (DGAPA) \\ albertopzmx@yahoo.com
}

\section{RESUMEN}

Respuesta al artículo "Problemas textuales en la edición de cuentos de Rubén Darío: 'El caso de la señorita Amelia", de Günther Schmigalle, publicado en el volumen 43 de Anales de Literatura Hispanoamericana.

Palabras clave: Darío, cuento.

Seven notes on miss very end of century

\begin{abstract}
Response to the article "Textual Problems in the edition of Rubén Darío's stories: 'El caso de la señorita Amelia'", by Günther Schmigalle, published in the volume 43 of Anales de Literatura Hispanoamericana.
\end{abstract}

Key words: Darío, short story.

La excelente edición y el establecimiento textual de "El caso de la señorita Amelia" de Rubén Darío a cargo de Günther Schmigalle (Anales, 2014, vol. 43, pp. 191-207) define la que a todas luces es la mejor lección posible de ese cuento inquietante que vio la luz justamente "le jour de l'an" (el primero de enero de 1894), en La Nación bonaerense. Ese trabajo estimula a prolongar la acuciosidad del hispanista germano.

1. Ignoro si la expresión sea vigente en "Hispania fecunda", como dice Darío, pero un hecho es cierto: en español americano antiguo y coloquial, de provincia y viejas familias, aquél que habrá mamado el niño Félix Rubén, se dice de un hijo o hija que "se quedó" cuando no llegó al matrimonio. Digamos, si tal mujer de 30 o 40 años sigue siendo soltera, es una solterona... "una quedada". Leemos en el cuento de Darío, por boca del enigmático doctor Z: "la cual [Amelia] se ha quedado en la infancia". Para los lectores hispanoamericanos es evidente el aprovechamiento de la expresión recién referida; Darío no usó al azar ese verbo infamante en voz pasiva: es la pasividad de los solterones que no salieron de la casa paterna: no maduraron 
sexualmente, no procrearon su propia descendencia, se quedaron el resto de su vida en el solio familiar. Lo que nos conduce a la ...

2. Segunda expresión coloquial: "niño viejo", "niña vieja"; designa al mismo tipo de miembro familiar. Ilustro con un caso que nos mantiene dentro del Modernismo. El destacado epígono mexicano Ramón López Velarde Berumen era un niño viejo, según alcancé a documentar con ancianos zacatecanos, seguramente hoy muertos, que tenían tratos con la familia materna del poeta (remito a Severino Salazar y Alberto Paredes, “¿Puede un dandy nacer en Tepetongo?”, múltiples ediciones hemerográficas en México, y en libro: Alberto Paredes, Pro Severino, Juan Pablos Editor-Instituto Zacatecano de Cultura, México, 2011, pp. 77-88). Recordemos que cuando López Velarde murió prematuramente a sus 33 años, en el número 71 de la entonces avenida Jalisco de la ciudad de México, vivía rodeado de su madre (doña Trinidad Berumen) y de sus hermanas que "solteras agonizaban".

En el cuento de Darío no aparece la expresión niña vieja, simplemente señalo aquí la afinidad, el deslizamiento conceptual de las expresiones coloquiales: haberse quedado, ser una quedada; ser la niña vieja de la familia.

3. Afirma Schmigalle: "El autor cambió el nombre del protagonista, mejor dicho la grafía de ese nombre". Puntual la observación pero creo que exagerada. Pasar de "el Dr. Z." a "el doctor Z" no es un cambio de nombre, sí de formulación. Lo que nos lleva a dos nociones: nombres formados por (o sólo por) iniciales, y acrónimos. Ejemplo mexicano muy posterior: un muy conocido homme de plume (poeta, traductor de poesía, narrador, ensayista), sumamente respetado firmaba persistentemente sus colaboraciones periodísticas y sus "versiones" (término suyo, que no traducciones) de poesía como JEP. Quién responde a esa denominación no era ningún misterio para nadie, ninguna forma de ocultamiento sino de modestia: José Emilio Pacheco concluyó su vida y obra colmado de honores y premios incluyendo el Cervantes. Existe además el uso literario de nombrar ciertos personajes con iniciales como nombre completo. La cultura alemana tiene la obra maestra epónima: M, filme de 1931, de Fritz Lang, con un hipnótico Peter Lorre encarnando la más magnética de las iniciales que vale por todo un nombre y su leyenda: M (en 1951 Joseph Losey, con nadie menos que Robert Aldrich como su asistente, cometió un muy digno remake, estelarizado por David Wayne). Otro uso de iniciales; en algunas lenguas como el inglés, preferir la mera letra en lugar de desatar los nombres e muy común: J. D. Salinger (1919-2010). Incluso en francés: J-K Huysmans es tan o más frecuente que Joris-Karl Huysmans. Así, considero que la forma más fluida de designar al protagonista masculino del cuento dariano es, efectivamente, "el doctor Z".

4. Increpa el doctor $\mathrm{Z}$ al personaje secundario que funge como narrador: "vuestro querido y admirado general Mansilla". Lamentablemente Schmigalle no anotó al 
personaje. Se trata de... Lucio Victorio Mansilla (Buenos Aires, 1831-pAris, 1913; al parecer residió en ésta desde 1896 hasta su muerte). Pertenece a una familia de militares de carrera e ilustrados; es hijo del coronel (federal) Lucio Norberto Mansilla y sobrino de nadie menos que Juan Manuel de Rosas. Existe una semblanza biográfica sobre Mansilla: Félix Luna (director de la colección), Lucio V. Mansilla, Planeta (Col. Grandes protagonistas de la historia Argentina), marzo 2001, ISBN 950-49-0678-8.

En otro momento de su obra Darío vuelve sobre la familia Mansilla: En Los raros, dentro del ensayo sobre "Augusto de Armas", se menciona al sobrino de Lucio Victorio, llamado éste Daniel García-Mansilla quien es hijo del también diplomático Manuel Rafael García Aguirre y de la escritora Eduarda Mansilla, hermana de nuestro general Lucio Victorio. Daniel era escritor bilingüe españolfrancés, estricto contemporáneo de RD (nacido en pAris, 1867-muerto ahí mismo en 1957); fue doctor en derecho, pionero del derecho de asilo (en 1936 recibió asilados españoles en Zarauz). Así que por lo pronto, tanto el general aparisinado como el sobrino que nació, vivió y murió ahí, ambos figuran en la vida y obra de Rubén Darío. La biografía social del nicaragüense está por hacerse.

5. Habla el doctor Z: "Hace veintitrés años, conocí en Buenos Aires a la familia Revall, cuyo fundador, un excelente caballero francés, ejerció un cargo consular en tiempo de Rosas." Esto nos da la cronología interna de la ficción de Darío. Lamentablemente, Schmigalle descuidó anotar a Rosas. Puede tratarse de dos épocas diferentes: 1. Gobernador de Buenos Aires (desde el 6/XII/1829, tiempo en el que promovió el Pacto Federal, hasta el 18/XII/32 cuando lo sucede Juan Ramón Balcarce). 2. Regresó como Gobernador de Buenos Aires (7/III/1835, fecha de la "Ley sancionada", confirmada el 13 de abril; fue derrotado por el general Justo José de Urquiza en la batalla de Caseros el 3/II/1852.)

Lo que permite inferir el lapso en que ubicaríamos al doctor $\mathrm{Z}$ hablando sobre la niña Amelia: cualquier año entre $1852(1829+23)$ y febrero de $1875(1852+23)$. Estemos conscientes que el autor tiene todo su derecho a manipular el calendario para beneficio de su ficción; Darío seguramente leyó a Lermina, Sinnett y quizás otros... pero el vehemente doctor $\mathrm{Z}$ sería terriblemente precoz en su culto oculto. De la bibliografía que aporta nuestro colega alemán, sólo hubiera podido conocer Incidents in the life of Madame Blavatsky, 1866, de Sinnett. Señalemos que Helena Petrovna von Han, $a$. Madame Blavatsky nació en 1831 y murió en 1891. Su Isis Unveiled (New York, 1877) es dos años posterior a nuestro terminus ante quem. $\mathrm{O}$ sea que Darío hizo viajar al futuro a su increíble doctor $\mathrm{Z}$.

6. De manera palmaria, dos son los aportes medulares del trabajo de Schmigalle: la fijación textual y la identificación de las fuentes bibliográficas teósificas y ocultistas que gravitan en el cuento, gracias a las cuales el estudioso puede enderezar las grafías utilizadas por Darío y distorsionadas por los sucesivos editores. Ciertamente 
este cuento es una de varias evidencias sobre el interés y conocimiento que el autor tenía de las diferentes expresiones de ocultismo entonces en boga. Schimgalle concluye que al comparar las grafías en Jules Lermina, La science occulte : magie pratique (pAris, E. Kohl, 1890) y en el cuento, esos usos y numerosos paralelismos "demuestran" cuál es la fuente del nicaragüense. El aporte de Schimgalle sobre la cultura ocultista y teosófica de Darío es de primera magnitud rebasando el caso específico que nos ocupa; no obstante considero que a pesar de la flagrancia, conviene introducir un cierto matiz: Darío debió haber usado y conocido al dedillo su Lermina, pero hasta que no aparezca una mención explícita por parte de nuestro escritor, en su obra o parafernalia, no hay certeza absoluta. El mismo Schimgalle remite a tres obras de Alfred Percy Sinnett (entre ellas Esoteric Buddhism, 1883 y 1885) como antecedente de Lermina y en su bibliografía nos enriquece con entradas de autores como Guaita, Papus y Schure. ¿Cómo saber si los leyó también o sólo a través de Lermina, por ejemplo?

En resumen, la relectura de "Amelia" regresa a la mesa dos temas urgentes: la complejidad del ocultismo y la teosofía en Darío y el terrible rompecabezas que sería intentar "reconstruir" sus lecturas (tanto en ejemplares suyos que habrá ido dejando a lo largo de su vida errante así como en préstamos de amigos y lecturas en bibliotecas públicas y privadas)... Darío fue un lector tan ávido y versátil que más bien hemos de preguntarnos qué no leyó.

7. Una nota estilística ahora que Schmigalle nos aclara la lectura de "El caso de la señorita Amelia".

Todo en ese bello relato de ambiente gótico sajón (Poe y Hawthorne, por supuesto), es un juego del Tiempo; de los tiempos verbales y narrativos.

Veámoslo bajo una analogía musical. Hay tres modos de tiempo, de tempo, en este cuento:

A) Duplicaciones anafóricas. Ya en el primer párrafo y desde la primera palabra del narrador: el que de condicional ("Que el doctor $\mathrm{Z}$ es ilustre, elocuente, conquistador; que su voz es profunda", etc). Nuevamente un condicional cuando el doctor Z toma la palabra ("si yo no estuviese", "si no supiese", etc). Más adelante se confirma el carácter reiterativo del personaje gracias a un modelo de frase de antecedente ("yo que he sido llamado sabio", etc). Todo lo cual desemboca con ostentosa oratoria en la mayestática afirmación "yo os digo que [...] y que". Podemos decir: tempo doppiato.

Reparemos que el desdibujado personaje que funge como narrador (siendo voz vicaria del autor) introduce el motivo formal de base, el cual pasa a la primera voz, el melancólico protagonista masculino, para que éste magnifique el recurso o tema formal.

B). Tempo narrativo. Ya instalado el recurso de las duplicaciones anafóricas, el narrador estimula al vehemente doctor $\mathrm{Z}$ a que cuente su anómala experiencia, cediéndole el discurso. Es él quien cuenta el caso límite, la experiencia más allá 
del común de los mortales. Darío coloca así el relato bajo la atmósfera justamente límite del mejor Poe. Las anomalías y los casos insólitos son un venero que explota el siglo XIX en esta suerte de admonición antipositivista y antirracionalista. "Me parece que ibais a demostrarnos que el tiempo..." aguijonea el narrador al doctor $\mathrm{Z}$ para meterlo de lleno en su tema: demostraciones de lo otro.

C) Ya tenemos relato encapsulado (el narrador cuenta que $\mathrm{Z}$ cuenta); puede entonces florecer la seducción del tiempo de los hábitos, los días y los placeres, el placer de los gestos consuetudinarios. Momento de evocar con delectación las recurrentes visitas del doctor $\mathrm{Z}$ a las señoritas Revall. Se configura un ritual doméstico en tono menor y sotto voce. Pues los rituales, caros a los niños y a la magia, se basan no en innovaciones (tiempo lineal que se fuga) sino en fidelidades que crean círculos hechiceros. Darío era un filólogo nato, un mago verbal. El núcleo poderoso de ese tempo reiterato es una frase que vuelve, casi con magia proustiana: “¿YY mis bombones?’ He aquí la pregunta sacramental.” Sacramental por parte del viejo oficiante que sin saberlo exige ese congelamiento del río del tiempo:

[...] es Amelia, la misma que yo dejé hace veintitrés años, la cual se ha quedado en la infancia, ha contenido su carrera vital. Se ha detenido para ella el reloj del Tiempo, en una hora señalada, -quién sabe con qué designio del desconocido Dios!

Por cierto que el diablo de la errata se coló en el desenlace: donde dice "Se he detenido" evidentemente se conjuga en impersonal con "ha". Nótese también el recurso inusual y dinámico por el que Darío abre la última frase con guión y la cierra con signo de admiración (que no se abrió).

Resumiendo: duplicaciones anafóricas, sintaxis paralelística, flujo discursivo del relato, tiempo de los hábitos, tiempo de los rituales, el largo periplo elíptico del protagonista adulto, todo ello se conjuga para sacar a luz la monstruosidad subyacente en una frase banal, emitida como en un suspiro por el narrador, quien, felix culpa de imprudencia, obliga a reaccionar al enigmático doctor $\mathrm{Z}$ : “ $\mathrm{OOh}$ si el tiempo pudiera detenerse!"

Todo lo cual inserta este cuento galante en la noble estirpe del short-story como humorada macabra al estilo de Poe y seguidores. (En una época posterior a Darío, el relato corto norteamericano ofrecerá la obra maestra sobre este tipo de mujeres: 1930, "A Rose for Emily" de William Faulkner.) Pues el tiempo, terriblemente, existe: conjurarlo ha provocado un involuntario e irresponsable hechizo del calendario, el surgimiento penitente de un fantasma cuya persona no ha muerto, la niña que literalmente se quedó, una niña vieja; no obstante... "El doctor $\mathrm{Z}$ era en este momento todo calva." 